\title{
Intersectionality and ADVANCE
}

When Association for Women in Science (AWIS) Executive Director and CEO Janet Koster asked me to open this plenary with a keynote focused on intersectionality, I indicated my doubts about being an appropriate individual. Most of the original, substantive work on intersectionality had been done by African American women such as bell hooks, Kimberle Crenshaw, and Patricia Hill Collins. When she responded that she had asked me because I know ADVANCE and have been with it since the beginning, I agreed to talk about intersectionality and ADVANCE.

The term intersectionality describes the overlap of reciprocally constructing phenomena an individual experiences because of gender, race/ethnicity, class, sexuality, religion, country of origin and education, age, disabilities, and other social identities to create a whole that is different from the component identities. The framework of intersectionality that arose from feminist (bell hooks, 2014 [1984]) and critical race theory (Kimberle Crenshaw, 1989), explains how related systems of oppression, domination or discrimination depend upon and reinforce each other to lead to systemic injustice and social inequality. Since policies and laws usually attempt to correct only one form of marginalized identity rather than interlocking multiple oppressed identities, intersectional identities may be overlooked or ignored.

For example, many of the laws and policies that address gender discrimination in ways experienced by white women, may overlook the discrimination women of color experience due to their race and gender. Similarly, laws that seek to rectify discrimination due to race/ethnicity, may ignore gender discrimination. Neither suffices to address the discrimination experienced by an African American woman, who embodies the intersection of race and gender. 
In a similar fashion, lesbians or transgender women are likely to face discrimination because of both their gender and their sexuality. If the lesbian or transgender woman also is a woman of color and/or has a physical disability, sexism, racism, lesbo- or transphobia, and ableism form an interlocking and reinforcing matrix of oppression and power. All aspects of an individual's identity need to be examined simultaneously as interacting with each other and affecting privilege and perception in society, rather than separately.

As I indicated previously, intersectionality grew out of feminist theory when it was articulated by bell hooks (1982) that the experience of middle class white women did not accurately represent the feminist movement as a whole and especially the situation for women of color where gender was not the primary determinant factor. Intersectionality theory was coined in 1989 by Kimberle Crenshaw, a legal scholar, who explored male violence against women, specifically rape and domestic violence, demonstrating that women of color experience this violence differently because of an intersection of both racism and sexism and that the laws to address male violence against women marginalize women of color, decreasing its visibility.

Black feminist theorist Patricia Hill Collins built on the work of hooks and Crenshaw. Collins (2000; 2009 [1990]; 2015) demonstrated that cultural patterns of oppression are bound together and influenced by race, gender, class, and ethnicity to form intersectional systems in society or "interlocking oppressions". This has led some to point out how these interlocking oppressions lead women to experience differences within the same society and environment. The political stances that often result from this have been summed up colloquially as "where you sit is where you stand". People in this room may hear this presentation differently or have differing perspectives on what is said, depending upon their experiences and social identities, both personally and professionally. 
You may be wondering how intersectionality applies to ADVANCE. ADVANCE was conceived back in 1998-99, as a result of the recognition that the percentage of women had not increased significantly by providing awards to individual women to further their research in most of the disciplines funded by National Science Foundation (NSF) (in some cases for more than five decades). It was realized that a structural approach, rather than an individual approach, was needed to "transform" science, technology, engineering and mathematics (STEM) and academic institutions to increase the numbers and percentages of women and particularly to advance them to leadership positions such as department chair, dean, provost, and president.

When the first cohort of awards was given in 2001, the initiative was critiqued because most of the awards had gone to public R-1 institutions. Since those institutions attract relatively fewer people of color and people of lower socio-economic status, it was suggested that class and race had been ignored in the attempt to correct for gender discrimination, thereby marginalizing women scientists who were not white and middle to upper class.

Over the years, NSF took these critiques to heart, reflecting a recognition of intersectionality both in its program solicitation, especially indicating that it welcomed primarily undergraduate and URM serving institutions to apply, and in its awards to such institutions. NSF also began to understand other types of intersectionality, in addition to race, class and gender, such as the importance of disciplinary diversity. Program solicitations strongly encouraged involvement of faculty from the social sciences and women's studies, as well as the traditional sciences and engineering, both in the leadership and research of ADVANCE projects. It also began to consider the role of other groups outside of academia, such as industry and the professional societies such as AWIS, who influence the experience of women scientists and the scientific culture and practice in terms of awards, leadership, and policies. 
Now, as ADVANCE continues to evolve, other intersectionalities experienced by women scientists such as their sexualities, physical and mental abilities, country of origin and education, and age are beginning to be recognized, as significant portions of the interlocking matrix. Just as the experiences of LGBTQI scientists have only recently begun to be examined and explored, with the concomitant recognition of the need for change regarding certain discriminatory expectations and practices in science, the situation for older women scientists remains largely overlooked and understudied.

Over time, many of us have come to a growing awareness of the intersectionalities affecting our own lives, in general, and in STEM in particular. Some of these were with us from the beginning but we become aware of them as we mature, have more experiences, and understand better societal structures. Others, such as our class, ability status, or age, may change over time. So, too, has the ADVANCE initiative become increasingly aware of intersectionalities over time and changed with that awareness and understanding. 


\section{References}

Collins, Patricia Hill (2009) [1990]. Black feminist thought: Knowledge, consciousness, and the politics of empowerment. New York: Routledge.

Collins, Patricia Hill (2000). Gender, black feminism, and black political economy. Annals of the American Academy of Political and Social Science. Sage. 568(1): 41-53.

Collins, Patricia Hill. (2015). Intersectionality's Definitional Dilemmas. Annual Review of Sociology. 41: 1- 20.

Crenshaw, Kimberle (1989). Demarginalizing the intersection of race and sex: A Black feminist critique of antidiscrimination doctrine, feminist theory and antiracist politics. University of Chicago Legal Forum. 140: 139-167.

hooks, bell (1982). Ain't I a woman: Black women and feminism. London, Boston: South End Press.

hooks, bell (2014) [1984]. Feminist theory: From margin to center ( $3^{\text {rd }}$ edition). New York: Routledge. 